\title{
A Multi-Objective Modeling Approach for Integrated Manufacturing and Preventive Maintenance Planning
}

\author{
Kamran S. Moghaddam \\ Department of Marketing and Supply Chain Management, College of Business, \\ Clayton State University, Morrow, GA 300260, USA \\ Email: KamranMoghaddam@ clayton.edu
}

\begin{abstract}
This research studies the effects of preventive maintenance and replacement activities on operational costs, overall reliability, and availability of a multi-tasking manufacturing machine. A multi-objective optimization model to find Pareto-optimal preventive maintenance and replacement schedules for a repairable multi-component machine with increasing failure rate is developed. The planning horizon is divided into equally-sized periods in which minimal repairs, full replacement, or do-nothing actions can be performed on each machine's component. The machine reliability for preventive maintenance aspects, its availability for production purposes, and total operational costs for both preventive maintenance and manufacturing planning are formulated as the objective functions and the multi-objective model is solved using a simulation-based optimization algorithm in real case study. It is shown that the developed mathematical models and the solution method can effectively generate Pareto-optimal preventive maintenance schedules that can be integrated into aggregate production plans.
\end{abstract}

Keywords: preventive maintenance, manufacturing machines, multi-objective optimization, simulation-based optimization

\section{INTRODUCTION}

Recent technological complexity of modern manufacturing machines has increased the level of inherent interdependencies between production plans and maintenance operations in these systems. In order to keep up with the current competitions in global markets, many manufacturing industries have developed highly automated production systems with computerized and sophisticated equipment. In order to be economically viable, these modern and expensive systems must be operated to their highest level of production capacity. When an unplanned unavailability caused by a manufacturing machine failure or even a planned downtime to perform necessary maintenance actions occur it affects the machine's availability and reduces the overall system's productivity. As a result, the original production plans become obsolete. Production plan modifications are usually time consuming and very expensive and often cause increased variability in output quality as well as in service level. Therefore, it is very important to integrate production plans and preventive maintenance schedules so that these plans get aligned to reduce the likelihood of the unexpected failures as well as the need for re-planning modifications.

In most manufacturing companies, production processes are fully integrated and a failure of one of the machines may halt the entire process to complete shutdown resulting to delays with significant technical and economic consequences. As such, significant productivity loss and additional costs including poor product quality, production overtimes, and customer dissatisfactions are expected if an integrated production system is not properly maintained. Like any other multi-component system when a production system is operating regularly, its various components are subject to degradations due either age or usage or both. Some of these degradations can be modeled or approximated by well-known stochastic processes models that can be used to optimally integrate production and preventive maintenance plans. In practice however, production and maintenance are usually planned independently.

Production planning models try to optimize the costs of setting up and operating the system including production and inventories costs. Maintenance scheduling models, on the other hand, is aimed to find costs and benefits trade-offs of implementing appropriate maintenance plans in order to optimize the performance of the production system. As such, preventive maintenance plans are closely related to production planning in manufacturing systems. In manufacturing setting, preventive maintenance activities are planned to implement maintenance or restoration of equipment to a specific state guaranteeing a desired service level. Production planning and preventive maintenance operations often conflict with each other because maintenance actions are generally considered as secondary thoughts in manufacturing systems in which the production is the core business function.

Different aspects of integrating production planning and preventive maintenance in repairable manufacturing systems have been extensively addressed in the literature. However, it is frequently tackled at the operational level (e.g., the production and maintenance scheduling) (Assid et al., 2015). Because the complexity of the problem highly depends on number of machines or components, majority of the studies have based their modeling approach on singlemachine production maintenance scheduling (Sortrakul et al., 2005; Aggoune and Portmann, 2006; Sortrakul and Cassady, 2007; Yildirim and Nezami, 2014; Zhao et al., 2014; Bouslah et al., 2016a; Bouslah et al., 2016b, EmamiMehrgani et al., 2016; Kang and Subramaniam, 2018; Alimian et al., 2019; Bahria et al., 2019; Liu et al., 2019; Duffuaa et al., 2020; Ghaleb et al., 2020; and Kolus et al., 2020).

Exact solution methods such as Branch-and-Bound (BB) for integer and mixed-integer programming models, 
and Generalized Reduced Gradient (GRG2) algorithm for nonlinear programming models have been employed in the literature mostly for single-machine models or for smallscale multi-machine situations (Cassady and Kutanoglu, 2003; Aghezzaf et al., 2007; Aghezzaf and Najid, 2008; Nourelfath and Chatelet, 2012; Portioli-Staudacher and Tantardini, 2012; Bajestani et al., 2014; Yalaoui et al., 2014; Kumar and Lad, 2017; Ao et al., 2019; and Polotski et al., 2019).

It has been reported that most integrated production and maintenance scheduling problems, with availability constraints, under different machine configurations and various objective functions are NP-hard problems (Kubiak et al., 2002). Because of this restraining feature, various heuristic and metaheuristic algorithms such as Genetic Algorithms (GA) and Simulated Annealing (SA) have been employed to tackle these problems (Aggoune and Portmann, 2006; Wang, 2013; Zhao et al., 2014; Ettaye et al., 2018).

Computer Numerical Control (CNC) machines are very important equipment in automated manufacturing systems. CNC machines use digitized data such as a computer and Computer Aided Manufacturing (CAM) program to control, automate, and monitor the operations of the machine (McNeel.com, 2016). The machine can be a milling machine, lathe, router, welder, grinder, laser or waterjet cutter, sheet metal stamping machine, robot, or many other types of machines. Since the CNC machines are repairable systems the failure characteristics of components as well as costs of possible preventive maintenance and replacement actions along with unexpected failure expenses can be estimated from the recorded historical data.

In this research, we develop a multi-objective mathematical model for a $\mathrm{CNC}$ machine by considering the equipment reliability for preventive maintenance purposes, the overall availability of the system for production aspects, and total operational costs for both preventive maintenance and manufacturing planning decisions. The manufacturing planning aspect of the model is captured by downtime costs and the overall availability of the system. This modeling approach enables the production planner to obtain trade-off solutions (aka, compromise solutions), with regard to three objectives, by which the efficient frontier can be identified. The remainder of this manuscript is organized as follows: in order to identify the gaps in the body of knowledge, the relevant literature is reviewed in Section 2. The problem description and formulation along with its difficulty aspects are illustrated in Section 3. In Section 4, the motivations behind the development of solution method are discussed. Computational results including presentation of a practical example, properties and practicality of the optimal solutions, and validation of the model and solution algorithm are presented in Section 5. Section 6 summarizes the contribution of the study and provides direction for future research and expansion.

\section{LITERATURE REVIEW}

\subsection{Applications: Single-Machine vs. Multi- Machine}

\subsubsection{Single-Machine Models}

Maintenance planning literature typically addresses the relationship between maintenance and production scheduling on a tactical level where the production process is limited to a single machine and with an explicit mathematical model representing machine deterioration (Bajestani et al., 2014). An early integrated model that simultaneously determines production scheduling and preventive maintenance planning decisions to minimize the total weighted tardiness of jobs was proposed by Cassady and Kutanoglu (2003). In that study, the integrated modelling approach and its performance is compared against the cases of solving the production scheduling and preventive maintenance planning problems independently. The numerical results showed an average 30\% reduction in expected total weighted tardiness. Multiple objective functions including minimization of maintenance cost, makespan, total weighted completion time of jobs, total weighted tardiness, and maximization of machine availability were considered in the work of Yulan et al. (2008). They used a multi-objective genetic algorithm to solve the integrated problem of production and preventive maintenance scheduling originally introduced by (Cassady and Kutanoglu, 2003).

A significant portion of the literature is devoted to the cost minimization through combined preventive maintenance and production control policies (Wang and Liu, 2013; Yalaoui et al., 2014; Wang and Liu, 2015; and Nourelfath et al., 2016). A production system subject to random failures in which any maintenance action in a period would reduce the system's production capacity is studied by Aghezzaf et al. (2007). The objective in their study is to find an integrated lot-sizing and preventive maintenance strategy for a system to minimize the expected sum of production and maintenance costs while satisfying the demand without back-orders. Aghezzaf et al. (2016) also formulated a more practical integrated model as a mixed-integer nonlinear optimization problem for which a linearization approach is also developed to reduce the complexity issues of solving such model. An integrated production scheduling and preventive maintenance planning model is proposed as a minimax problem of weighted tardiness by incorporating both for a job-shop problem with single-machine (Pan et al., 2010).

Suliman and Jawad (2012) formulated a mathematical model to optimize the preventive maintenance intervals and lot sizes for a single-unit single-item production system. Their proposed model considers average total costs of the maintenance, inventory holding, non-conforming items, and shortage over the planning horizon. In another study, an integrated mathematical model for a multi-product, multiperiod, single-machine manufacturing system to minimize the total cost of production, inventory, energy, maintenance, minimal repair along with energy consumption constraints is developed by Yildirim and Nezami (2014). Lu et al. (2015) addressed the integrated problem for a single machine in which optimal sequence of jobs, preventive maintenance times, and jobs' completion times can be determined simultaneously. More complex integrated production, maintenance, and quality control model for an imperfect process in a multi-period multi-product single-machine under capacitated lot-sizing assumptions is also discussed in Nourelfath et al. (2016). 


\subsubsection{Multi-Machine Models}

A job shop is a type of manufacturing setting in which low-quantity high-variety of custom products are produced. In a job shop environment, most products require unique setups and production sequences and priorities. In flow shop systems, on the other hand, in order to achieve a smooth and less interrupted production flow, production processes are mostly designed in a linear structure in which minimization of machines' idle times is the highest priority. Singlemachine models have been successfully used in job shop problems whereas multi-machine models are more appropriate for flow shop situations that take production and inventory planning into consideration.

In order to find an optimal integrated lot-sizing and preventive maintenance strategy for a multi-state system with production and maintenance costs and demand constraints, Machani and Nourelfath (2012) proposed a variable neighborhood search as a solution method. Nourelfath and Chatelet (2012) also dealt with the integrated problem at a tactical level in which products must be produced in lots during a finite planning horizon with demand requirements. Fitouhi and Nourelfath (2014) embedded a noncyclical preventive maintenance with tactical production planning in a multi-state system to determine a combined lot-sizing strategy and preventive maintenance operations. Sitompul and Aghezzaf (2011) formulated a two-level hierarchical aggregate and detailed planning in which preventive maintenance is integrated into the aggregate planning while corrective maintenance actions are embedded into the operational planning. In the study of Portioli-Staudacher and Tantardini (2012), six case studies were used to investigate the economic effects of rescheduling of preventive maintenance activities in production systems. Wang and Liu (2015) developed a multi-objective parallel machine scheduling model to simultaneously minimize the makespan of the operations and the unavailability of the machines. Multi-machine multi-period and multi-product production systems are studied by Yalaoui et al. (2014) in which a polyhedral-based optimal relaxation method is developed to improve the computational time of the proposed model. An integrated production and maintenance scheduling in a deteriorating multi-machine production system over multi-period planning horizon is analyzed using Markov decision process modeling approach (Bajestani et al., 2014). A proactive approach to solve integrated production scheduling and maintenance planning problem in a multi-component flow shop application is developed by Cui et al. (2018) in order to optimize the bi-objective of quality robustness and solution robustness with failure uncertainty. In another study, Chansombat et al. (2018) presents a novel mixed integer linear programming model for simultaneously solving the integrated problem for a multicomponent production system in the capital goods industry.

\subsection{Solution Methods: Exact vs. Heuristics vs. Simulation}

\subsubsection{Exact Solution Methods}

Najid et al. (2011) addressed the problem of finding optimal production lot sizes of various items by taking into account demand shortage and the reliability of the production line. Dhouib et al. (2012) formulated a joint optimization model of production-inventory control and preventive maintenance policy for a manufacturing cell. They assumed that the production-inventory control policy should be able to build and maintain a security stock of finished products in order to respond to demand and to avoid shortages during overhaul periods. Kuo and Chang (2007) studied production scheduling for a fixed number of jobs to be processed by a single machine and the maintenance planning during the processing times. They presented an optimal integrated plan for a single machine subject to cumulative damage process and investigated the effects of optimal preventive maintenance plan on production schedules with the goal to minimize the total tardiness.

A branch-and-bound algorithm to solve an integrated optimization model for a single machine is developed by Wang and Liu (2013). Different variations of the algorithm by changing lower bounds, dominance rules, and upper bounds are tested to enhance the performance of the algorithm on randomly generated problems. EmamiMehrgani et al. (2016) extended a previous work on cooptimization of production and corrective and preventive maintenance by investigating the impact of human error on repairable manufacturing systems subject to random failure over an infinite planning horizon and its impact on system capacity and inventory policies.

\subsubsection{Heuristics Solution Methods}

Sortrakul et al. (2005) and Sortrakul and Cassady (2007) developed effective solution methods based on genetic algorithms for solving a large-scale version of integrated production maintenance problem to minimize total weighted expected tardiness. The integrated problem in multi-line production systems subject to failures is studied by Aghezzaf and Najid (2008) in which a Lagrangian-based heuristic procedure to solve a nonlinear mixed-integer model is proposed. In order to measure the optimality gaps, generated test problems were solved using lower bounds obtained from a linear mixed-integer sub-model. AlaouiSelsouli et al. (2012) presented a Lagrangian relaxationbased heuristic to solve a mixed-integer linear programming model for a joint production maintenance problem.

Li et al. (2010) formulated an integrated scheduling model to minimize the total production costs using a genetic algorithm. The results showed that this integrated optimal policy is much more practical than the optimal maintenance planning and decision sequence given by the independent models. A production system is modeled as a multi-state system with binary-states, and state-independent components by Nourelfath et al. (2010) and solved using a genetic algorithm. Uzun and Ozdogan (2012) showed how a procedure based on genetic algorithm is successfully applied to determine optimal production maintenance policies. Series of experiments to analyze the effects of maintenance parameters on the production performance such as completion time and maximum machine availability were also conducted. Wang (2013) deals with an integrated biobjective optimization problem for production scheduling and preventive maintenance in a single-machine context with sequence-dependent setup times. In order to solve this integrated problem, the author employed NSGA-II and SPEA2 evolutionary algorithms to find an approximation of the Pareto-optimal front. In order to minimize the total production costs, preventive maintenance costs, and minimal 
repair costs, Xiao et al. (2016) proposed an integrated optimization model solved by random parameter genetic algorithms. Boudjelida (2019) developed ants colony optimization, genetic algorithm, tabu search and some hybridizations of these methods to tackle the integrated production and maintenance scheduling under uncertainties.

\subsubsection{Simulation Methods}

If the modeling approach considers uncertainty in the parameters such as supplier quality rating, customers demand, machine quality rating, etc., along with probability distributions for these parameters, incorporation of simulation-based methods (e.g., simulation-based optimization) would be an appropriate way to cope with the uncertainties. Simulation-based optimization methods combine computer simulation with optimization techniques such as exact methods, evolutionary algorithms, and the Response Surface Methodology to heuristically solve analytically or numerically ill-structured problems (Tekin and Sabuncuoglu, 2004; Gosavi, 2015; and Ekin, 2018).

Assid et al. (2015) presented a control policy to accurately imitate the production system behavior and to optimize the joint production maintenance control policy parameters using combined continuous/discrete event simulation models. Bouslah et al. (2016b) proposed a type-1 continuous sampling plan (CSP-1) along with make-to-stock production and maintenance policies for a production system under quality and reliability deteriorations. For both plans, the optimization problem is to minimize the total cost subject to outgoing quality constraint. Series of numerical examples are discussed to demonstrate the effectiveness of the solution approach and to analyze the interactions among production, inventory, quality, maintenance, and reliability aspects. The study is further expanded to meet customer requirements by considering an average outgoing quality limit (AOQL) constraint in their optimization problem (Bouslah et al., 2016a). Purohit and Lad (2016) assume demand, supply, and machine yield as ransom variables and developed an integrated model to determine optimal production lot size, assembly-specific preventive maintenance schedule, and job sequencing for a multi-component machine. In the study of Kumar and Lad (2017) the goal is to find optimal production schedule and maintenance plan by which the total operational cost is minimized. A simulation-based optimization method to solve the problem is employed and it is found that for various scenarios the integrated approach reduces the total cost up to $36 \%$ compared to independent modeling approaches. A stochastic mathematical model for an integrated problem of production lot sizing, quality control, and condition-based maintenance is formulated and solved by a simulation-based optimization approach coupling Monte Carlo Simulation and Response Surface Methodology (Cheng et al., 2018).

\subsection{Contributions of this Research}

In order to identify potential gaps in the body of knowledge, the characteristics of modeling approach in relevant literature is reviewed and analyzed. Table $\mathbf{1}$ summarizes the reviewed literature based on the application, model type, objective functions, and the solution methods. The last row of the table also highlights the features of our developed model. We found that although there have been much extensive work in the literature, majority of the published articles dealt with single-machine or singlecomponent production systems and more sophisticated multi-component systems have received less attention. Furthermore, reliability and availability aspects of integrated manufacturing and preventive maintenance planning have not been studied in-depth compared to the models with cost minimization or equivalent criteria (e.g., makespan). This provides us an opportunity to extend the previous work of multi-component systems by incorporating multiobjective modeling approach with total operational cost, overall system reliability, and overall system availability. The contributions of this research are summarized as follows:

1. A new multi-component multi-objective model is formulated to simultaneously minimize total operational cost and maximize the reliability and availability for a CNC machine in which its components are degrading due to heavy use and tight production schedule.

2. A new simulation-based goal programming optimization algorithm to solve the multi-objective model and to obtain the Pareto-optimal preventive maintenance schedules is developed. The most important advantage of this hybrid algorithm is that it does not require prior preferences of the objective functions from the decision maker and would let him/her select the desired Pareto-optimal solution based on other higher-level information generated from different operational scenarios or policies.

\section{PROBLEM DESCRIPTION AND FORMULATION \\ 3.1 Maintenance and Replacement Operations}

We consider a repairable multi-tasking manufacturing machine with $N$ components. Most repair models assume that repairs result in making the component function "as good as new." In other words, the component is replaced after each failure. It is frequently the case that repairs consist of replacing or restoring only a small percentage of the parts or components composing the machine. This leaves the machine in approximately the same condition (age) it was in just prior to the failure. It is also assumed that each component in the machine is subject deterioration due to age and usage with an increasing rate of occurrence of failure. A useful and somewhat natural way to model this situation is to treat it as a stochastic point process. However, to model this stochastic process, an intensity function, $\rho(t)$, should be defined as the rate of change of the expected number of failures is time dependent.

$$
\begin{aligned}
& \rho(t)=\frac{d E[N(t)]}{d t} \\
& E[N(t)]=\int_{0}^{t} \rho\left(t^{\prime}\right) d t^{\prime}
\end{aligned}
$$


Table 1 Characteristics of modeling approach in the reviewed literature

\begin{tabular}{|c|c|c|c|c|c|c|c|c|c|c|}
\hline \multirow{2}{*}{ Reference } & \multicolumn{2}{|c|}{ Application } & \multicolumn{2}{|c|}{ Model type } & \multicolumn{3}{|c|}{ Objective function(s) } & \multicolumn{2}{|c|}{ Solution method } & \multirow[b]{2}{*}{ Simulation } \\
\hline & Single-machine & Multi-machine & Deterministic & Stochastic & Cost/Time & Reliability & Availability & Exact & Heuristics & \\
\hline (Aggoune and Portmann, 2006) & + & & + & & + & & & & + & \\
\hline (Aghezzaf et al., 2007) & + & & + & & + & & & + & & \\
\hline (Aghezzaf et al., 2016) & + & & + & & + & & & & + & \\
\hline (Aghezzaf and Najid, 2008) & + & & + & & + & & & + & + & \\
\hline (Alaoui-Selsouli et al., 2012) & + & & + & & + & & & & + & \\
\hline (Alimian et al., 2019) & + & & & + & + & & & + & & \\
\hline (Ao et al., 2019) & & + & & + & + & & & + & & \\
\hline (Assid et al., 2015) & + & & & + & + & & & & + & + \\
\hline (Bahria et al., 2019) & + & & + & & + & & & + & & \\
\hline (Bajestani et al., 2014) & & + & & + & + & & & + & & \\
\hline (Boudjelida, 2019) & & + & & + & + & & & & + & \\
\hline (Bouslah et al., 2016a) & + & & & + & + & & & + & + & + \\
\hline (Bouslah et al., 2016b) & + & & & + & + & & & + & + & + \\
\hline (Cassady and Kutanoglu, 2003) & + & & + & & + & & + & + & & \\
\hline (Chansombat et al., 2018) & & + & + & & + & & & + & & \\
\hline (Cheng et al., 2018) & + & & & + & + & + & & & & + \\
\hline (Cui et al., 2018) & & + & & + & + & + & & & + & + \\
\hline (Dhouib et al., 2012) & + & & + & & + & & & + & & \\
\hline (Duffuaa et al., 2020) & + & & + & & + & & & + & & \\
\hline (Ekin, 2018) & + & & & + & + & & & & + & + \\
\hline (Emami-Mehrgani et al., 2016) & + & & & + & + & & & + & & \\
\hline (Ettaye et al., 2018) & + & & + & & + & & & & + & \\
\hline (Fitouhi and Nourelfath, 2014) & & + & + & & + & & & & + & \\
\hline (Ghaleb et al., 2020) & + & & & + & + & & & & + & \\
\hline (Kang and Subramaniam, 2018) & + & & & + & + & & & + & & \\
\hline (Kolus et al., 2020) & + & & + & & + & & + & + & & \\
\hline (Kubiak et al., 2002) & & + & + & & + & & & + & & \\
\hline (Kumar and Lad, 2017) & & + & + & & + & & & & + & + \\
\hline (Kuo and Chang, 2007) & + & & + & & + & & & + & & \\
\hline (Li et al., 2010) & + & & + & & + & & & & + & \\
\hline (Liu et al., 2019) & + & & + & & + & & & + & & \\
\hline (Lu et al., 2015) & + & & + & & + & + & & & + & \\
\hline (Machani and Nourelfath, 2012) & & + & + & & + & & & & + & \\
\hline (Najid et al., 2011) & + & & + & & + & & & + & & \\
\hline (Nourelfath and Chatelet, 2012) & & + & + & & + & & & + & & \\
\hline (Nourelfath et al., 2010) & & + & + & & + & & & & + & \\
\hline (Nourelfath et al., 2016) & + & & + & & + & & & + & & \\
\hline (Pan et al., 2010) & + & & + & & + & & & + & & \\
\hline (Polotski et al., 2019) & + & & & + & + & & & + & & \\
\hline (Portioli and Tantardini, 2012) & & + & + & & + & & & + & & \\
\hline
\end{tabular}


Table 1 Characteristics of modeling approach in the reviewed literature (cont)

\begin{tabular}{|c|c|c|c|c|c|c|c|c|c|c|}
\hline \multirow{2}{*}{ Reference } & \multicolumn{2}{|c|}{ Application } & \multicolumn{2}{|c|}{ Model type } & \multicolumn{3}{|c|}{ Objective function(s) } & \multicolumn{3}{|c|}{ Solution method } \\
\hline & Single-machine & Multi-machine & Deterministic & Stochastic & Cost/Time & Reliability & Availability & Exact & Heuristics & Simulation \\
\hline (Purohit and Lad, 2016) & & + & & + & + & & & & + & + \\
\hline (Sitompul and Aghezzaf, 2011) & & + & + & & + & & & + & & \\
\hline (Sortrakul and Cassady, 2007) & + & & + & & + & & & & + & \\
\hline (Sortrakul et al., 2005) & + & & + & & + & & & & + & \\
\hline (Suliman and Jawad, 2012) & + & & + & & + & & & & + & \\
\hline (Uzun and Ozdogan, 2012) & + & & + & & & & + & & + & \\
\hline (Wang, 2013) & + & & + & & + & + & & & + & \\
\hline (Wang and Liu, 2013) & + & & + & & + & & & + & & \\
\hline (Wang and Liu, 2015) & & + & + & & + & & + & & + & \\
\hline (Xiao et al., 2016) & & + & + & & + & & & & + & \\
\hline (Yalaoui et al., 2014) & & + & + & & + & & & + & + & \\
\hline (Yildirim and Nezami, 2014) & + & & + & & + & & & + & & \\
\hline (Yulan et al., 2008) & + & & + & & + & & + & & + & \\
\hline (Zhao et al., 2014) & + & & + & & + & & & & + & \\
\hline Our developed model & & + & + & & + & + & + & + & & + \\
\hline
\end{tabular}


Because of increasing failure rate and maintainability assumption of the machine under study, it is assumed that components failure follows the Non-Homogeneous Poisson Process (NHPP). The Non-Homogeneous Poisson Process is similar to the conventional Poisson process but the rate of occurrence of failure is not constant and instead is a function of time. A common form for the intensity function which is called the power law process or the Weibull process is presented in equation (3). Table 2 lists the notations for sets, indices, decision variables, and parameters used to develop and express the multi-objective optimization model in this study.

$$
\rho_{i}(t)=\lambda_{i} \cdot \beta_{i} \cdot t^{\beta_{i}-1} \quad \forall i \in N, \lambda_{i}, \beta_{i}>0
$$

Table 2 List and description of notations

\begin{tabular}{|c|c|}
\hline Sets & Description \\
\hline $\bar{N}$ & Set of components \\
\hline$T$ & Set of periods during the aggregate planning \\
\hline$K$ & Set of objective functions \\
\hline Indices & Description \\
\hline$i$ & Index for component $i, i \in N$ \\
\hline$t$ & Index for time interval $t, t \in T$ \\
\hline$k$ & Index for objective function $k, k \in K$ \\
\hline Decision Variables & Description \\
\hline$x_{i, t}$ & Effective age of component $i$ at the start of period $t, i \in N, t \in T$ \\
\hline$x_{i, t}^{\prime}$ & Effective age of component $i$ at the end of period $t, i \in N, t \in T$ \\
\hline$m_{i, t}$ & $\begin{array}{l}\text { Binary variable equals to } 1 \text { if component } i \text { is minimally repaired at the end of period } t, i \in N, t \in T \text {, otherwise it is } \\
\text { equal to } 0 \text {. }\end{array}$ \\
\hline$r_{i, t}$ & $\begin{array}{l}\text { Binary variable equals to } 1 \text { if component } i \text { is replaced or repaired at the end of period } t, i \in N, t \in T \text {, otherwise it is } \\
\text { equal to } 0 \text {. }\end{array}$ \\
\hline Parameters & Description \\
\hline$L$ & Length of the aggregate planning usually between $1-2$ years \\
\hline$\lambda_{i}$ & Scale parameter of intensity function for component $i, i \in N$ \\
\hline$\beta_{i}$ & Shape parameter of intensity function for component $i, i \in N$ \\
\hline$\phi_{i}$ & Improvement factor function for maintenance action on component $i, i \in N$ \\
\hline$M C_{i}$ & Maintenance (including inspection and minimal repair) cost of component $i, i \in N$ \\
\hline$R C_{i}$ & Replacement cost of component $i, i \in N$ \\
\hline$F C_{i}$ & Unexpected failure cost of component $i, i \in N$ \\
\hline$P M T_{i}$ & Required time for preventive maintenance action on component $i, i \in N$ \\
\hline$R T_{i}$ & Required time for replacement action on component $i, i \in N$ \\
\hline$D C$ & Downtime cost of the manufacturing machine \\
\hline$f_{k}$ & Objective function $k, k \in K$ \\
\hline $\operatorname{goal}_{k}$ & Designated goal for objective function $f_{k}, k \in K$ \\
\hline$w_{k}$ & Deviation weight from a designated goal $_{k}$ for objective function $f_{k}, k \in K$ \\
\hline$d_{k}^{+}$ & Positive deviation from a designated goal $_{k}$ for objective function $f_{k}, k \in K$ \\
\hline$d_{k}^{-}$ & Negative deviation from a designated goal $_{k}$ for objective function $f_{k}, k \in K$ \\
\hline
\end{tabular}

Production and maintenance planners are interested in finding an optimal schedule of maintenance and replacement actions for each component over the aggregate planning interval $[0, L]$. The time interval $[0, L]$ is divided into $T$ discrete periods, each with equal length of $L / T$. At the end of each period $t$, a component can be either minimally maintained, replaced, or no action is to be taken. In most manufacturing systems, when a machine has an increasing failure rate, the duration of its function after repairs will become shorter and shorter resulting in a finite functioning time. Similarly, as the machine ages, its repair time will become longer and longer and will tend to infinity as such, the machine becomes non-repairable (Elsayed, 2012).

It is assumed that preventive maintenance activities in period $t$ can reduce the "effective age" of the components and subsequently the "failure rate" of the machine. This kind of maintenance activities are known as minimal repairs in the literature since they do not change the failure rate or characteristic of the machine instead they just push back effective age of the components. In order to keep track of instantaneous changes in component's age and failure rate, let $x_{i, t}$ denote the effective age of component $i$ at the start of period $t$, and $x_{i, t}^{\prime}$ denote the age of component $i$ at the end of period $t$. The relationship between $x_{i, t}$ and $x_{i, t}^{\prime}$ can be expressed using equation (4).

$$
x_{i, t}^{\prime}=x_{i, t}+(L / T) \quad \forall i \in N, t \in T
$$

If a component $i$ is minimally repaired at the end of a period, the maintenance action effectively reduces the effective age of the component at the start of the next period as shown in equation (5). The function $\phi$ is called "improvement factor" that allows for a variable effect of maintenance on an aging component. When $\phi=0$, the minimal repair action restores the component age to a state of "good-as-new" (i.e., replacement). When $\phi=1$, the minimal repair action has no effect on the component age and the component remains in a state of "bad-as-old" (i.e., do nothing). Note that the minimal repair action at the end of period $t$ can partially lower the failure rate of component $i$. The minimal repair action also requires duration of $P M T_{i}$ to be done with a cost of $M C_{i}$ incurred at the end of the period.

$$
x_{i, t+1}=\phi\left(R C_{i}, M C_{i}\right) \cdot x_{i, t}^{\prime} \quad \forall i \in N, t \in T
$$


The improvement factor function used here is based on the ratio of difference of replacement and minimal repair costs as presented in equation (6). If a costly minimal repair action is performed on a component, the effective age of the component improves more than when an inexpensive maintenance is executed. As such, more expensive maintenance results in a greater amount of age reduction and failure rate improvement (Moghaddam and Usher, 2010). Note that if the minimal repair cost approaches to the replacement cost, the numerator of the fraction will approach to zero, and the minimal repair action will be equivalent to a replacement action (which is a very rare case). Conversely, if the minimal repair cost is very close to zero, the improvement factor ratio will approach to one (i.e., maintenance has no effect on the effective age and it is equivalent to do nothing action).

$$
\phi\left(R C_{i}, M C_{i}\right)=\left(R C_{i}-M C_{i}\right) / R C_{i} \quad \forall i \in N
$$

If a machine component is replaced at the end of a period with a new identical component, then the effective age of the replaced component at the start of the next period starts at zero according to equation (7). Subsequently, the component failure behavior is returned to the state of "good- as-new" in which the failure rate of the component drops from $\rho_{i}\left(x_{i, t}^{\prime}\right)$ to $\rho_{i}(0)$. The replacement action takes, $R T_{i}$, to be done and requires a replacement cost of $R C_{i}$. Finally, if no maintenance action is taken during a period $t$, then a continuous increase in the effective age and the failure rate of the component is expected, as shown in equations (8)-(9).

$$
\begin{aligned}
& x_{i, t+1}=0 \quad \forall i \in N, t \in T \\
& x_{i, t+1}=x_{i, t}^{\prime} \quad \forall i \in N, t \in T \\
& \rho_{i}\left(x_{i, t+1}\right)=\rho_{i}\left(x_{i, t}^{\prime}\right) \quad \forall i \in N, t \in T
\end{aligned}
$$

When a future schedule of maintenance actions for a manufacturing machine is planned, the inevitable costs caused by unexpected component failures should be also considered in planning schedules. Since the component failure is a random variable, it is not possible to exactly determine when the unexpected failures will happen and the calculation of expected number of failures for each component in each period is usually proposed. The single unexpected failure cost for each component is estimated as $F C_{i}$ and then the expected cost of component failures in each period is calculated using equations (10)-(11).

$$
\begin{aligned}
& F_{i, t}=F C_{i} .\left(\text { Expected number of failures in }\left[x_{i, t}, x_{i, t}^{\prime}\right]\right) \\
& F_{i, t}=F C_{i} \cdot \int_{x_{i, t}}^{x_{i, t}^{\prime}} \rho_{i}(t) d t=F C_{i} \cdot \lambda_{i}\left(\left(x_{i, t}^{\prime}\right)^{\beta_{i}}-\left(x_{i, t}\right)^{\beta_{i}}\right) \quad \forall i \in N, t \in T \\
& \text { Total Downtime Costs }=\sum_{t=1}^{T}\left[D C\left(1-\prod_{i=1}^{N}\left(1-\left(m_{i, t}+r_{i, t}\right)\right)\right)\right]
\end{aligned}
$$

In a multi-component production system with failure, maintenance, and replacement costs, one may reduce the integrated scheduling problem to a simple task of finding the independent optimal sequence of minimal repair, replacement, or do-nothing actions for each component. As a result, a simple but impractical sequence of operations for each component regardless of other maintenance actions taken on the other components can be found. It seems economically and operationally advantageous in combining series of maintenance and replacement actions to be simultaneously performed. For instance, while the machine is shut down to replace a component the maintenance crew can perform repair or replacement actions on some other components, even if they do not require any minimal repair or replacement actions. Components maintenance dependency can be modeled by considering a downtime cost to be charged if any component (one or more) is minimally repaired or replaced in any given period. Equation (12) calculates the total downtime costs charged whenever a machine component in each period is minimally repaired or

replaced. It can be verified that if more than one component
$f_{1}=\sum_{i=1}^{N} \sum_{t=1}^{T}\left[F C_{i} \cdot \lambda_{i}\left(\left(x_{i, t}^{\prime}\right)^{\beta_{i}}-\left(x_{i, t}\right)^{\beta_{i}}\right)+M C_{i} \cdot m_{i, t}+R C_{i} \cdot r_{i, t}\right]+\sum_{t=1}^{T}\left[D C\left(1-\prod_{i=1}^{N}\left(1-\left(m_{i, t}+r_{i, t}\right)\right)\right)\right]$

$\operatorname{Reliability}(t)=\exp \left(-\int_{0}^{t} \rho\left(t^{\prime}\right) d t^{\prime}\right)$ 


$$
\begin{aligned}
& \operatorname{Rel}_{i, t}=\exp \left(-\int_{x_{i, t}}^{x_{i, t}^{\prime}} \lambda_{i} \cdot \beta_{i} \cdot t^{\beta_{i}-1} d t\right)=\exp \left(-\lambda_{i}\left(\left(x_{i, t}^{\prime}\right)^{\beta_{i}}-\left(x_{i, t}\right)^{\beta_{i}}\right)\right) \quad \forall i \in N, t \in T \\
& f_{2}=\prod_{i=1}^{N} \prod_{t=1}^{T}\left[\exp \left(-\lambda_{i}\left(\left(x_{i, t}^{\prime}\right)^{\beta_{i}}-\left(x_{i, t}\right)^{\beta_{i}}\right)\right)\right]
\end{aligned}
$$

$$
\text { Availability }=\frac{M T T F}{M T T F+M T T R}
$$

$$
\begin{aligned}
A_{i, t} & =\frac{\left(x_{i, t}^{\prime}-x_{i, t}\right)}{\left(x_{i, t}^{\prime}-x_{i, t}\right)+R T_{i} \cdot \lambda_{i}\left(\left(x_{i, t}^{\prime}\right)^{\beta_{i}}-\left(x_{i, t}\right)^{\beta_{i}}\right)+\left(P M T_{i} \cdot m_{i, t}+R T_{i} \cdot r_{i, t}\right)} \quad \forall i \in N, t \in T \\
f_{3} & =\prod_{i=1}^{N} \prod_{t=1}^{T}\left[\frac{\left(x_{i, t}^{\prime}-x_{i, t}\right)}{\left(x_{i, t}^{\prime}-x_{i, t}\right)+R T_{i} \cdot \lambda_{i}\left(\left(x_{i, t}^{\prime}\right)^{\beta_{i}}-\left(x_{i, t}\right)^{\beta_{i}}\right)+\left(P M T_{i} \cdot m_{i, t}+R T_{i} \cdot r_{i, t}\right)}\right]
\end{aligned}
$$

In order to formulate the machine reliability, first it is required to formulate the reliability function for each repairable component $i$ in period $t$. It is proven that the reliability of a repairable comment can be calculated using its intensity function as in equation (14) according to (Elsayed, 2012). Replacing $\rho_{i}(t)$ using equation (3) and taking the integral, we can calculate the reliability of component $i$ in period $t$, equation (15).

In this research, we intend to model the failure behavior of a multi-component manufacturing machine in which the production operations require that all components of the machine function flawlessly. Without loss of generality, we can assume that the machine components are arranged in series and this will help us to formulate the machine reliability function based on its individual components reliabilities by equation (16).

A machine component may become unavailable because of the occurrence of unexpected failures resulting to the case of repair or replacement of the failed or faulty component. A minimal repair action normally takes some time, $P M T_{i}$, and replacement actions need time to replacement, $R T_{i}$, to be carried over. On the other hand, a component may become unavailable because of scheduled minimal repairs or replacement activities. Finally, If no preventive maintenance or replacement action is performed on a component, the likelihood of component unavailability increases over time and eventually resulting to the component failure due to increase of failure rate.

The general form of the system availability can be expressed as equation (17) where MTTF is the Mean Time to Failure and MTTR is the Mean Time to Repair for a failed system. The availability function for a repairable component $i$ in period $t$ can be generalized from equation (17) to reflect two cases of unavailability. Considering $x_{i, t}^{\prime}-x_{i, t}$ as the equivalent to MMTF along with time to perform minimal repair and replacement actions, the availability of component $i$ is formulated as equation (18).

Similar to the reliability function, the availability of the series system of components can be formulated by the product of individual components' availability over a specified number of periods as shown in equation (19).

\subsection{Multi-Objective Optimization Model for Multi-Component Machine}

Based on the descriptions and formulation presented above, the multi-objective nonlinear mixed-integer optimization model for the integrated manufacturing and preventive maintenance planning with the total operational costs, overall reliability, and system availability can be expressed as follows:

$$
\begin{aligned}
& \operatorname{Min} f_{1}=\sum_{i=1}^{N} \sum_{t=1}^{T} {\left[F C_{i} \cdot \lambda_{i}\left(\left(x_{i, t}^{\prime}\right)^{\beta_{i}}-\left(x_{i, t}\right)^{\beta_{i}}\right)+M C_{i} \cdot m_{i, t}+R C_{i} \cdot r_{i, t}\right] } \\
&+\sum_{t=1}^{T}\left[D C\left(1-\prod_{i=1}^{N}\left(1-\left(m_{i, t}+r_{i, t}\right)\right)\right)\right]
\end{aligned}
$$

$\operatorname{Max} f_{2}=\prod_{\substack{i=1 \\ N}}^{N} \prod_{\substack{T=1 \\ T}}^{T}\left[\exp \left(-\lambda_{i}\left(\left(x_{i, t}^{\prime}\right)^{\beta_{i}}-\left(x_{i, t}\right)^{\beta_{i}}\right)\right)\right]$

$\operatorname{Max} f_{3}=\prod_{i=1}^{N} \prod_{t=1}^{T}\left[\frac{\left(x_{i, t}^{\prime}-x_{i, t}\right)}{\left(x_{i, t}^{\prime}-x_{i, t}\right)+R T_{i} \cdot \lambda_{i}\left(\left(x_{i, t}^{\prime}\right)^{\beta_{i}}-\left(x_{i, t}\right)^{\beta_{i}}\right)+\left(P M T_{i} \cdot m_{i, t}+R T_{i} \cdot r_{i, t}\right)}\right]$

Subject to

$x_{i, 1}=0 \quad \forall i \in N$

$x_{i, t}=\left(1-m_{i, t-1}\right)\left(1-r_{i, t-1}\right) x_{i, t-1}^{\prime}+m_{i, t-1}\left(\frac{R C_{i}-M C_{i}}{R C_{i}}\right) x_{i, t-1}^{\prime} \quad \forall i \in N, t \in T$

$x_{i, t}^{\prime}=x_{i, t}+(L / T) \quad \forall i \in N, t \in T$ 


$$
\begin{aligned}
& m_{i, t}+r_{i, t} \leq 1 \quad \forall i \in N, t \in T \\
& m_{i, t}, r_{i, t} \in\{0,1\} \quad \forall i \in N, t \in T \\
& x_{i, t}, x_{i, t}^{\prime} \geq 0
\end{aligned}
$$

In the above optimization model, the constraint (20) sets that the initial age to zero for each component as all components are supposed to be brand new at the beginning. The constraint (21) computes the effective age of components based on an action (minimal repair, replacement, or do nothing) that was performed in the previous period. If a component was replaced in the previous period, $r_{i, t-1}=1, m_{i, t-1}=0$, then its effective age drops down to $x_{i, t}=0$ fat the start of the next period, if a component is minimally repaired, $r_{i, t-1}=0, m_{i, t-1}=1$ then its effective age becomes $x_{i, t}=\left(\frac{R C_{i}-M C_{i}}{R C_{i}}\right) x_{i, t-1}^{\prime}$ as described earlier in equation (6). Finally if no action was taken, $r_{i, t-1}=$ $0, m_{i, t-1}=0$, the component continues its normal aging so its effective age at the start of next period will be equal to its effective age at the end of the previous period, i.e., $x_{i, t}=$ $x_{i, t-1}^{\prime}$. Constraint (22) reflects the relationship between starting and ending effective age of components. The necessary condition (23) must be held enforcing that only a minimal repair, or a replacement, or do nothing action should be performed on each component in each period. Constraint (24) restricts the primary decision variables to be binary and constraint (25) indicates that the starting and ending effective age variables are non-negative.

\section{SOLUTION METHOD}

Since multi-objective optimization problems have equally important Pareto-optimal solutions, an ideal solution method should be able to find multiple Pareto-optimal solutions at once and let the decision maker choose the desired solution based on other higher-level information (e.g., long term strategies, short term goals, and what-if scenarios). As such, the Pareto-optimal solutions found by an ideal method should be independent from the user's predefined input parameters. In the past three decades numerous multi-objective evolutionary algorithms have also been developed and tested as trustable and efficient solution methods to solve multi-objective models (Deb, 2011). But, the main disadvantage of these algorithms is that they are limited to obtaining good or near optimal solutions and achievement of exact optimal solution(s) is never guaranteed. The major drawback of the standard goal programming method as an exact method is that it can find only a single Pareto-optimal solution that is highly dependent to the decision maker's choice of the designated goals and the weights of deviation from the goals. In order to eliminate this dependability, the following simulation-based optimization algorithm is proposed in which randomly generated objective goals and deviation weights are employed in the goal programming submodel.

\subsection{Simulation-Based Goal Programming Optimization Start}

Compute the minimum and maximum values of the individual objective function $k, f_{k}^{\min }, f_{k}^{\max } \forall k \in K$

$$
f_{k}^{\text {normalized }}=\frac{f_{k}-f_{k}^{\text {min }}}{f_{k}^{\text {max }}-f_{k}^{\text {min }}} \quad \forall k \in K
$$

Current iteration $=1$

While (current iteration $\leq$ designated number of iterations)

Import the estimated parameters of the optimization model from the Excel file

$$
\begin{aligned}
& w_{k}=\operatorname{rand}(0,1) \quad \forall k \in K \\
& w_{k}^{\prime}=\frac{w_{k}}{\sum_{k=1}^{K} w_{k}} \quad \forall k \in K \\
& \text { goal }_{k}=\operatorname{rand}\left(f_{k}^{\text {min }}, f_{k}^{\text {max }}\right) \quad \forall k \\
& \text { goal }_{k}^{\text {normalized }} \in K \\
& =\frac{\text { goal }_{k}-f_{k}^{\text {min }}}{f_{k}^{\text {max }}-f_{k}^{\text {min }}} \quad \forall k \in K
\end{aligned}
$$

Solve the following Goal Programming submodel:

Min Weighted Goal Deviations $=$ $w_{1}^{\prime} d_{1}^{+}+w_{2}^{\prime} d_{2}^{-}+w_{3}^{\prime} d_{3}^{+}$

Subject to:
$f_{k}^{\text {normalized }}+\left(d_{k}^{-}+d_{k}^{+}\right)$
$=$goal $_{k}^{\text {normalized }} \quad \forall k \in K$

the set of constraints (20)-(25)

Current iteration $=$ Current iteration +1 End while

End

\section{CASE STUDY AND COMPUTATIONAL RESULTS}

\subsection{Data Setting}

In order to demonstrate an application of the developed model and show the effectiveness of the proposed solution method for a real multi-component machine, a case study is developed from a CNC metalworking machine. The reliability characteristics of the machine's components were determined from the historical components' failures, repairs and replacements. In addition to the failure characteristics of components, costs of possible preventive maintenance and replacement operations along with unexpected failure costs were estimated from charges recorded in accounting books as shown in Table 3. The downtime cost of the machine system is assumed to be $\$ 12,500$ per month for 24 months. It is also assumed that a minimal repair action (including inspection and some basic repair if required) takes $1 / 4$ of a working day (i.e., 4 hours) whereas a replacement action may require a full working day of a two 8-hour shifts (i.e., 16 hours). Visual Basic.Net programming is used to develop the computer simulation in which LINGO optimization software 
is utilized to solve the goal programming submodel on a laptop computer with Intel ${ }^{\circledR}$ Core $^{\mathrm{TM}}$ i7-6600U CPU @ 2.60 $\mathrm{GHz}$ and 16.00 GB RAM.

\subsection{Optimal Solutions for Individual Objective Functions}

Tables 4-6 show the optimal solutions with respect to each objective function independently, while ignoring the other objective functions, subject to the model's constraints (20)-(25). Table 4 illustrates the optimal preventive and replacement schedule for the total operational cost with lowest possible value of $\$ 95021$. As can be seen, the schedule calls for a single downtime in period 11 (almost in the middle of the planning horizon) to perform replacement action on only 8 components. The trade-off is to have a very unreliable machine likely to fail at any time or with highly degraded components by which the outputs will be substandard with major quality issues. Table 5, on the other hand, shows the optimal preventive and replacement schedule for the system reliability with highest possible value of 0.9234 . In this situation, the optimal schedule calls for shutting down the machine every month to perform replacement action on all components. This would be completely unrealistic from the operational aspect and also from the cost perspective. Finally, Table 6, demonstrates the optimal preventive and replacement schedule for the system availability measure with highest possible value of 0.8799 . Like the optimal schedule shown in Table 4, this optimal schedule calls for a single downtime at the middle of the planning horizon in period 12 to perform replacement actions on only 6 components. The drawbacks of implementing such a schedule is to have a very unreliable machine with highly degraded components. As discussed above, optimizing the systems maintenance schedule by only considering a single objective function results to an unacceptable scenario in which the other aspects of the system are completely compromised. In the next section, the proposed solution method is employed in order to capture the existing tradeoffs among objective functions.

Table 3 Characteristics of components in the production system

\begin{tabular}{cccccc}
\hline Components & Scale parameter & Shape parameter & Maintenance cost (\$) & Replacement cost (\$) & Failure cost (\$) \\
\hline 1 & 0.0034 & 2.18 & 592 & 2,369 & 7,107 \\
2 & 0.0031 & 2.04 & 750 & 3,000 & 9,000 \\
3 & 0.0028 & 2.08 & 461 & 1,844 & 5,532 \\
4 & 0.0037 & 1.94 & 682 & 2,728 & 8,184 \\
5 & 0.0030 & 1.81 & 567 & 2,269 & 6,807 \\
6 & 0.0025 & 2.15 & 642 & 2,569 & 7,707 \\
7 & 0.0021 & 2.18 & 565 & 1,260 & 6,780 \\
8 & 0.0018 & 1.93 & 453 & 2,872 & 5,439 \\
9 & 0.0024 & 1.87 & 718 & 2,716 & 8,616 \\
10 & 0.0022 & 2.13 & 679 & & 8,148 \\
\hline
\end{tabular}

Table 4 The optimal solution for the total operational cost $($ Minimum cost $=\$ 95021)$

\begin{tabular}{|c|c|c|c|c|c|c|c|c|c|c|c|c|c|c|c|c|c|c|c|c|c|c|c|c|}
\hline $\begin{array}{c}\text { Month/ } \\
\text { Component }\end{array}$ & 1 & 2 & 3 & 4 & 5 & 6 & 7 & 8 & 9 & 10 & 11 & 12 & 13 & 14 & 15 & 16 & 17 & 18 & 19 & 20 & 21 & 22 & 23 & 24 \\
\hline 1 & & & & & & & & & & & $r$ & & & & & & & & & & & & & \\
\hline 2 & & & & & & & & & & & $r$ & & & & & & & & & & & & & \\
\hline 3 & & & & & & & & & & & $r$ & & & & & & & & & & & & & \\
\hline 4 & & & & & & & & & & & $r$ & & & & & & & & & & & & & \\
\hline 5 & & & & & & & & & & & - & & & & & & & & & & & & & \\
\hline 6 & & & & & & & & & & & $r$ & & & & & & & & & & & & & \\
\hline 7 & & & & & & & & & & & $r$ & & & & & & & & & & & & & \\
\hline 8 & & & & & & & & & & & - & & & & & & & & & & & & & \\
\hline 9 & & & & & & & & & & & $r$ & & & & & & & & & & & & & \\
\hline 10 & & & & & & & & & & & $r$ & & & & & & & & & & & & & \\
\hline
\end{tabular}

Table 5 The optimal solution for the system reliability (Maximum reliability $=0.9234$ )

\begin{tabular}{|c|c|c|c|c|c|c|c|c|c|c|c|c|c|c|c|c|c|c|c|c|c|c|c|c|}
\hline $\begin{array}{c}\text { Month/ } \\
\text { Component }\end{array}$ & 1 & 2 & 3 & 4 & 5 & 6 & 7 & 8 & 9 & 10 & 11 & 12 & 13 & 14 & 15 & 16 & 17 & 18 & 19 & 20 & 21 & 22 & 23 & 24 \\
\hline 1 & $r$ & $r$ & $r$ & $r$ & $r$ & $r$ & $r$ & $r$ & $r$ & $r$ & $r$ & $r$ & $r$ & $r$ & $r$ & $r$ & $r$ & $r$ & $r$ & $r$ & $r$ & $r$ & $r$ & $r$ \\
\hline 2 & $r$ & $r$ & $r$ & $r$ & $r$ & $r$ & $r$ & $r$ & $r$ & $r$ & $r$ & $r$ & $r$ & $r$ & $r$ & $r$ & $r$ & $r$ & $r$ & $r$ & $r$ & $r$ & $r$ & $r$ \\
\hline 3 & $r$ & $r$ & $r$ & $r$ & $r$ & $r$ & $r$ & $r$ & $r$ & $r$ & $r$ & $r$ & $r$ & $r$ & $r$ & $r$ & $r$ & $r$ & $r$ & $r$ & $r$ & $r$ & $r$ & $r$ \\
\hline 4 & $r$ & $r$ & $r$ & $r$ & $r$ & $r$ & $r$ & $r$ & $r$ & $r$ & $r$ & $r$ & $r$ & $r$ & $r$ & $r$ & $r$ & $r$ & $r$ & $r$ & $r$ & $r$ & $r$ & $r$ \\
\hline 5 & $r$ & $r$ & $r$ & $r$ & $r$ & $r$ & $r$ & $r$ & $r$ & $r$ & $r$ & $r$ & $r$ & $r$ & $r$ & $r$ & $r$ & $r$ & $r$ & $r$ & $r$ & $r$ & $r$ & $r$ \\
\hline 6 & $r$ & $r$ & $r$ & $r$ & $r$ & $r$ & $r$ & $r$ & $r$ & $r$ & $r$ & $r$ & $r$ & $r$ & $r$ & $r$ & $r$ & $r$ & $r$ & $r$ & $r$ & $r$ & $r$ & $r$ \\
\hline 7 & $r$ & $r$ & $r$ & $r$ & $r$ & $r$ & $r$ & $r$ & $r$ & $r$ & $r$ & $r$ & $r$ & $r$ & $r$ & $r$ & $r$ & $r$ & $r$ & $r$ & $r$ & $r$ & $r$ & $r$ \\
\hline 8 & $r$ & $r$ & $r$ & $r$ & $r$ & $r$ & $r$ & $r$ & $r$ & $r$ & $r$ & $r$ & $r$ & $r$ & $r$ & $r$ & $r$ & $r$ & $r$ & $r$ & $r$ & $r$ & $r$ & $r$ \\
\hline 9 & $r$ & $r$ & $r$ & $r$ & $r$ & $r$ & $r$ & $r$ & $r$ & $r$ & $r$ & $r$ & $r$ & $r$ & $r$ & $r$ & $r$ & $r$ & $r$ & $r$ & $r$ & $r$ & $r$ & $r$ \\
\hline 10 & $r$ & $r$ & $r$ & $r$ & $r$ & $r$ & $r$ & $r$ & $r$ & $r$ & $r$ & $r$ & $r$ & $r$ & $r$ & $r$ & $r$ & $r$ & $r$ & $r$ & $r$ & $r$ & $r$ & $r$ \\
\hline
\end{tabular}


Table 6 The optimal solution for the system availability (Maximum availability $=0.8799$ )

\begin{tabular}{|c|c|c|c|c|c|c|c|c|c|c|c|c|c|c|c|c|c|c|c|c|c|c|c|c|}
\hline $\begin{array}{c}\text { Month/ } \\
\text { Component }\end{array}$ & 1 & 2 & 3 & 4 & 5 & 6 & 7 & 8 & 9 & 10 & 11 & 12 & 13 & 14 & 15 & 16 & 17 & 18 & 19 & 20 & 21 & 22 & 23 & 24 \\
\hline 1 & & & & & & & & & & & & $r$ & & & & & & & & & & & & \\
\hline 2 & & & & & & & & & & & & $r$ & & & & & & & & & & & & \\
\hline 3 & & & & & & & & & & & & $r$ & & & & & & & & & & & & \\
\hline 4 & & & & & & & & & & & & - & & & & & & & & & & & & \\
\hline 5 & & & & & & & & & & & & - & & & & & & & & & & & & \\
\hline 6 & & & & & & & & & & & & $r$ & & & & & & & & & & & & \\
\hline 7 & & & & & & & & & & & & $r$ & & & & & & & & & & & & \\
\hline 8 & & & & & & & & & & & & - & & & & & & & & & & & & \\
\hline 9 & & & & & & & & & & & & - & & & & & & & & & & & & \\
\hline 10 & & & & & & & & & & & & $r$ & & & & & & & & & & & & \\
\hline
\end{tabular}

\subsection{Structure of the Pareto-Optimal Solutions}

Tables 7-9 depict examples of Pareto-optimal schedules by running three different modifications using generated random goals based on uniform distribution, generated random goals based on normal distribution, and the objective functions' ideal goals of the simulation-based optimization algorithm. First, it is important to mention most minimal repair and replacement actions shown to be performed in the same period (in a column-based pattern) capturing the effect of the downtime penalty cost. Another finding to be noted is that once a minimal repair or replacement action recommended to be performed on a component, do nothing actions will follow the action previously taken for subsequent periods. The Tables 7-9 also provide the random weights, random goals, and optimal values of the objective functions for each schedule instance.

It should be noted that the developed mathematical model and solution method in this research can handle medium-scale problems with 100-200 components over 2-3 years of planning horizon. However, for large-scale problems with more than 500 components obtaining the exact optimal solution(s) would be very time-consuming if not impossible. In those cases, it is recommended to develop special-purpose heuristic or metaheuristic algorithms to be able to get the near-optimal solutions which in many cases are satisfactorily enough for practical applications.

Table 7 A Pareto-optimal schedule with uniform random goals and random deviation weights

$\left(\mathrm{w}_{1}=0.1956, \mathrm{w}_{2}=0.4175, \mathrm{w}_{3}=38.69, \mathrm{goal}_{1}=\$ 187408, \mathrm{goal}_{2}=0.7324\right.$, goal $\left._{3}=0.6713\right)$ $($ Cost $=\$ 223930$, Reliability $=0.7104$, Availability $=0.6010)$

\begin{tabular}{|c|c|c|c|c|c|c|c|c|c|c|c|c|c|c|c|c|c|c|c|c|c|c|c|c|}
\hline $\begin{array}{c}\text { Month/ } \\
\text { Component }\end{array}$ & 1 & 2 & 3 & 4 & 5 & 6 & 7 & 8 & 9 & 10 & 11 & 12 & 13 & 14 & 15 & 16 & 17 & 18 & 19 & 20 & 21 & 22 & 23 & 24 \\
\hline 1 & & & & $r$ & & & $r$ & & & $r$ & & & $r$ & & & $r$ & & & $r$ & & & $r$ & & \\
\hline 2 & & & & $r$ & & & $\mathrm{~m}$ & & & $r$ & & & $r$ & & & $\mathrm{~m}$ & & & $r$ & & & $\mathrm{~m}$ & & \\
\hline 3 & & & & $r$ & & & $r$ & & & $r$ & & & $\mathrm{~m}$ & & & $r$ & & & $r$ & & & $r$ & & \\
\hline 4 & & & & $\mathrm{~m}$ & & & $r$ & & & $\mathrm{~m}$ & & & $r$ & & & $r$ & & & $r$ & & & $\mathrm{~m}$ & & \\
\hline 5 & & & & - & & & $r$ & & & $\mathrm{~m}$ & & & $r$ & & & $\mathrm{~m}$ & & & $r$ & & & $\mathrm{~m}$ & & \\
\hline 6 & & & & $r$ & & & $r$ & & & $r$ & & & $r$ & & & $\mathrm{~m}$ & & & $r$ & & & $r$ & & \\
\hline 7 & & & & $r$ & & & $r$ & & & $r$ & & & $r$ & & & $r$ & & & $\mathrm{~m}$ & & & $r$ & & \\
\hline 8 & & & & $\mathrm{~m}$ & & & $r$ & & & $\mathrm{~m}$ & & & $r$ & & & $r$ & & & $r$ & & & $r$ & & \\
\hline 9 & & & & $r$ & & & $r$ & & & $\mathrm{~m}$ & & & $r$ & & & $\mathrm{~m}$ & & & $r$ & & & $\mathrm{~m}$ & & \\
\hline 10 & & & & $\mathrm{~m}$ & & & $r$ & & & $r$ & & & $r$ & & & $r$ & & & $r$ & & & $r$ & & \\
\hline
\end{tabular}

Table 8 A Pareto-optimal schedule with normal goals and random deviation weights

$\left(\mathrm{w} 1=0.5627, \mathrm{w}_{2}=0.1238, \mathrm{w}_{3}=0.3135\right.$, goal $_{1}=\$ 272334$, goal $_{2}=0.6836$, goal $\left._{3}=0.7541\right)$

$($ Cost $=\$ 195937$, Reliability $=0.6511$, Availability $=0.5769)$

\begin{tabular}{|c|c|c|c|c|c|c|c|c|c|c|c|c|c|c|c|c|c|c|c|c|c|c|c|c|}
\hline $\begin{array}{c}\text { Month/ } \\
\text { Component }\end{array}$ & 1 & 2 & 3 & 4 & 5 & 6 & 7 & 8 & 9 & 10 & 11 & 12 & 13 & 14 & 15 & 16 & 17 & 18 & 19 & 20 & 21 & 22 & 23 & 24 \\
\hline 1 & & & $r$ & & & $r$ & & & $r$ & & & $\mathrm{~m}$ & & & $r$ & & & $r$ & & & $r$ & & $\mathrm{~m}$ & \\
\hline 2 & & & $r$ & & & $\mathrm{~m}$ & & & $r$ & & & $r$ & & & $r$ & & & $\mathrm{~m}$ & & & $r$ & & $\mathrm{~m}$ & \\
\hline 3 & & & $r$ & & & $r$ & & & $r$ & & & $r$ & & & $r$ & & & $r$ & & & $r$ & & $\mathrm{~m}$ & \\
\hline 4 & & & $r$ & & & $r$ & & & $r$ & & & $r$ & & & $r$ & & & $r$ & & & $r$ & & - & \\
\hline 5 & & & $r$ & & & $\mathrm{~m}$ & & & $\mathrm{~m}$ & & & $\mathrm{~m}$ & & & $r$ & & & $\mathrm{~m}$ & & & $r$ & & $\mathrm{~m}$ & \\
\hline 6 & & & $r$ & & & $r$ & & & $r$ & & & $r$ & & & $r$ & & & $r$ & & & $r$ & & $r$ & \\
\hline 7 & & & $r$ & & & $r$ & & & $r$ & & & $r$ & & & $r$ & & & $r$ & & & $r$ & & $r$ & \\
\hline 8 & & & $\mathrm{~m}$ & & & - & & & $r$ & & & $\mathrm{~m}$ & & & $\mathrm{~m}$ & & & $r$ & & & $r$ & & $\mathrm{~m}$ & \\
\hline 9 & & & $r$ & & & $\mathrm{~m}$ & & & $r$ & & & - & & & $r$ & & & $r$ & & & $r$ & & - & \\
\hline 10 & & & $r$ & & & $r$ & & & $r$ & & & $r$ & & & $r$ & & & $\mathrm{~m}$ & & & $r$ & & $r$ & \\
\hline
\end{tabular}


Table 9 A Pareto-optimal schedule with the ideal goals and random deviation weights $\left(\mathrm{w}_{1}=0.0105, \mathrm{w}_{2}=0.6861, \mathrm{w}_{3}=0.3034, \mathrm{goal}_{1}=\$ 95021\right.$, goal $_{2}=0.9234$, goal $\left._{3}=0.8799\right)$ $($ Cost $=\$ 449677$, Reliability $=0.8327$, Availability $=0.4873)$

\begin{tabular}{ccccccccccccccccccccccccc}
\hline $\begin{array}{c}\text { Month/ } \\
\text { Component }\end{array}$ & $\mathbf{1}$ & $\mathbf{2}$ & $\mathbf{3}$ & $\mathbf{4}$ & $\mathbf{5}$ & $\mathbf{6}$ & $\mathbf{7}$ & $\mathbf{8}$ & $\mathbf{9}$ & $\mathbf{1 0}$ & $\mathbf{1 1}$ & $\mathbf{1 2}$ & $\mathbf{1 3}$ & $\mathbf{1 4}$ & $\mathbf{1 5}$ & $\mathbf{1 6}$ & $\mathbf{1 7}$ & $\mathbf{1 8}$ & $\mathbf{1 9}$ & $\mathbf{2 0}$ & $\mathbf{2 1}$ & $\mathbf{2 2}$ & $\mathbf{2 3}$ & $\mathbf{2 4}$ \\
\hline 1 & $\mathrm{r}$ & $\mathrm{r}$ & $\mathrm{r}$ & $\mathrm{r}$ & $\mathrm{r}$ & $\mathrm{r}$ & $\mathrm{r}$ & $\mathrm{r}$ & & $\mathrm{r}$ & & $\mathrm{r}$ & $\mathrm{r}$ & $\mathrm{m}$ \\
2 & $\mathrm{r}$ & $\mathrm{r}$ & $\mathrm{r}$ & $\mathrm{r}$ & $\mathrm{r}$ & $\mathrm{r}$ & $\mathrm{r}$ & $\mathrm{r}$ & & $\mathrm{r}$ & & $\mathrm{m}$ & $\mathrm{r}$ & $\mathrm{r}$ \\
3 & $\mathrm{r}$ & - & $\mathrm{r}$ & $\mathrm{r}$ & $\mathrm{r}$ & $\mathrm{r}$ & $\mathrm{r}$ & - & & $\mathrm{r}$ & & $\mathrm{r}$ & $\mathrm{m}$ & $\mathrm{r}$ \\
4 & $\mathrm{r}$ & - & $\mathrm{r}$ & $\mathrm{m}$ & $\mathrm{r}$ & $\mathrm{r}$ & $\mathrm{r}$ & $\mathrm{r}$ & & $\mathrm{m}$ & & $\mathrm{r}$ & $\mathrm{r}$ & $\mathrm{m}$ \\
5 & $\mathrm{~m}$ & $\mathrm{~m}$ & $\mathrm{r}$ & $\mathrm{r}$ & - & $\mathrm{r}$ & $\mathrm{m}$ & $\mathrm{m}$ & $\mathrm{r}$ & $\mathrm{m}$ & $\mathrm{r}$ & $\mathrm{m}$ \\
6 & $\mathrm{r}$ & $\mathrm{r}$ & - & $\mathrm{r}$ & $\mathrm{r}$ & - & $\mathrm{r}$ & $\mathrm{r}$ & $\mathrm{r}$ & $\mathrm{r}$ & $\mathrm{m}$ & $\mathrm{r}$ \\
7 & $\mathrm{r}$ & $\mathrm{r}$ & $\mathrm{r}$ & $\mathrm{r}$ & $\mathrm{r}$ & $\mathrm{r}$ & $\mathrm{r}$ & $\mathrm{r}$ & & $\mathrm{r}$ & & $\mathrm{r}$ & $\mathrm{r}$ & $\mathrm{r}$ \\
8 & $\mathrm{~m}$ & $\mathrm{r}$ & $\mathrm{m}$ & $\mathrm{r}$ & - & $\mathrm{m}$ & $\mathrm{m}$ & $\mathrm{r}$ & & $\mathrm{r}$ & & $\mathrm{m}$ & $\mathrm{m}$ & $\mathrm{m}$ \\
9 & - & $\mathrm{r}$ & - & $\mathrm{r}$ & $\mathrm{r}$ & $\mathrm{r}$ & $\mathrm{m}$ & $\mathrm{r}$ & & $\mathrm{r}$ & & $\mathrm{r}$ & $\mathrm{m}$ & $\mathrm{r}$ \\
10 & $\mathrm{r}$ & $\mathrm{r}$ & $\mathrm{r}$ & $\mathrm{r}$ & $\mathrm{r}$ & $\mathrm{r}$ & $\mathrm{r}$ & $\mathrm{r}$ & & $\mathrm{r}$ & & $\mathrm{r}$ & $\mathrm{r}$ & $\mathrm{m}$ \\
\hline
\end{tabular}

\subsection{Distribution of the Pareto-Optimal Solutions}

The first milestone in solving a multi-objective optimization problem is to generate non-dominated solutions close enough to the Pareto-optimal front. The second feature in the solution algorithm is that the generated non-dominated solutions must be uniformly and widely distributed in the Pareto-optimal area capturing the trade-off, if there is any, among different objective functions. Figure 1 illustrates the Pareto-optimal solutions of the objective functions from uniformly generated random goals and deviation weights on a plot-matrix graph. It can be verified that the Pareto-optimal solutions uniformly cover a broad area of the objective functions' space enabling them to capture the existing tradeoff between the operational cost, reliability, and availability of the machine.
The effect of the other probability distributions to generate random goals on the performance of the algorithm is also tested by generating random goals from a normal distribution as shown in Figure 2. This modification generates non-dominated solutions clustered around the mean of the normal distribution, $\left(f_{k}^{\max }+f_{k}^{\min }\right) / 2$. Being clustered makes the non-dominated solutions incapable of capturing the entire trade-off of the objectives as seen in Figure 2 so the third task (covering the entire area of the objectives' space) in multi-objective solution procedure is not fully achievable using the random goals generated from the normal distribution.

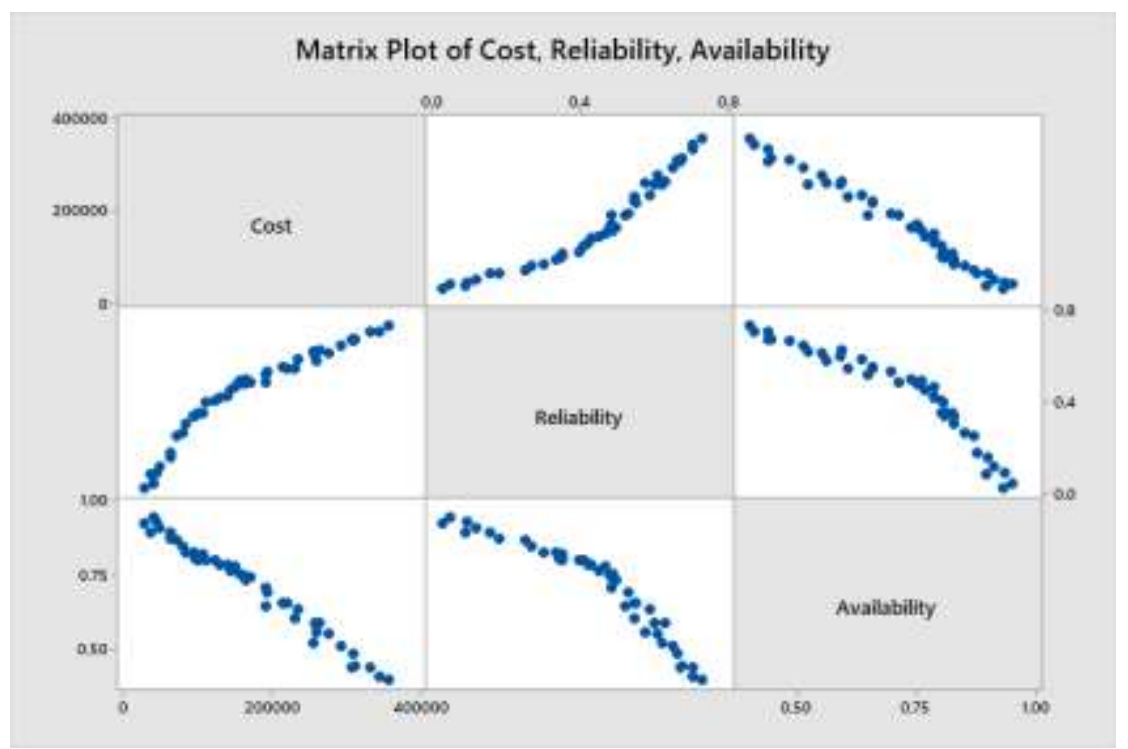

Figure 1 Distribution pattern of Pareto-optimal solutions using generated uniform random goals 


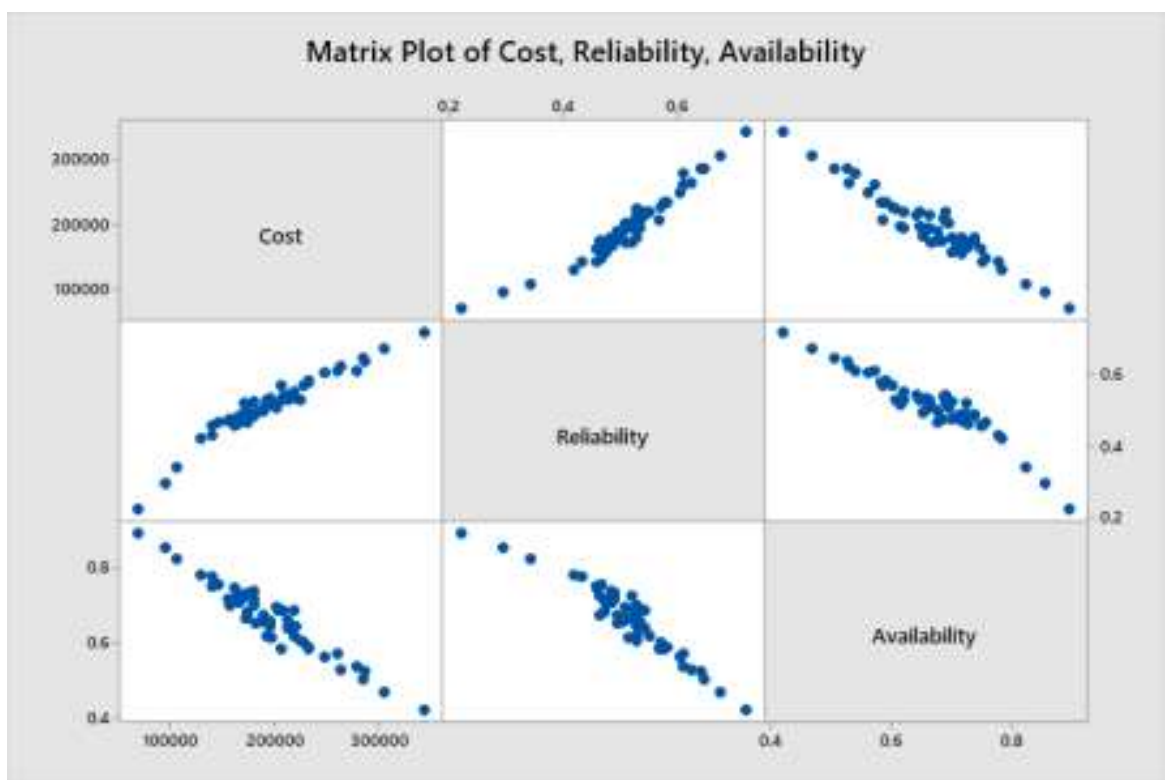

Figure 2 Distribution of Pareto-optimal solutions using generated normal random goals

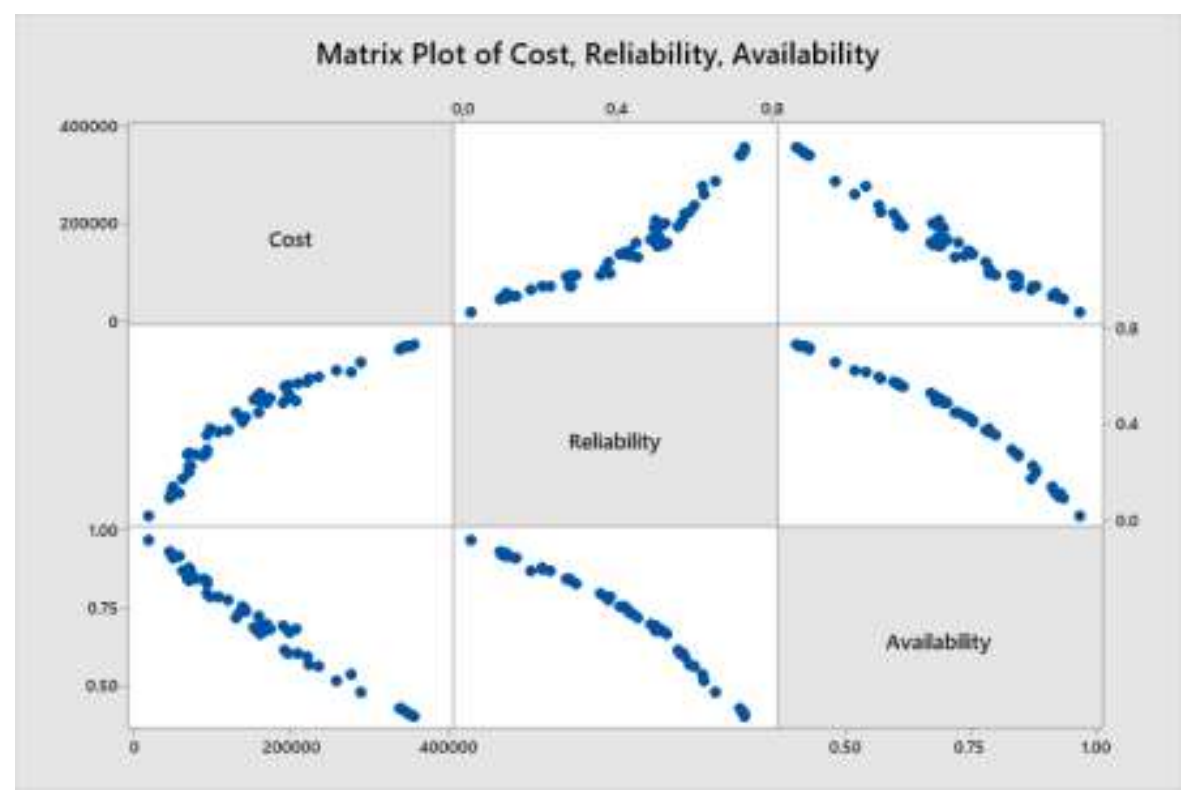

Figure 3 Distribution of Pareto-optimal solutions using ideal goals

Another modification is tested by incorporating deterministic ideal goals of the objective functions, $f_{k}^{\max }$ and $f_{k}^{\min }$, along with generated random weights. This modification generates a different pattern of Pareto-optimal solutions forming better trade-off curves than the ones obtained by normal goals in reaching to the extreme values of the objectives as shown in Figure 3. However, this comes with an expense in which some areas in the objectives space are uncovered resulting to loss of uniformity (the second task of solving a multi-objective model is not achieved). However, it should be noted that the Pareto-optimal solutions generated from the ideal goals are not as good as the Pareto-optimal solutions generated from random goals in fulfilling the three tasks of solving multi-objective problems.

\section{CONCLUSIONS AND DIRECTIONS FOR FUTURE RESEARCH}

In this study, a new multi-objective nonlinear mixedinteger optimization model to find Pareto-optimal maintenance and replacement schedules for a repairable manufacturing machine is developed. In addition, a simulation-based optimization algorithm is also presented. The proposed model and the solution method are found to be useful approach in solving maintenance and replacement planning problems faced in automated manufacturing systems such as CNC machines. The study could identify non-dominated solutions close enough to the Pareto optimal front and uniformly distributed over the objectives space revealing existing trade-offs among different objective functions. 
We have identified two areas for future research and expansion. The first area would be incorporation of uncertainty features to some deterministic parameters of the model such as downtime cost which is in most cases is very challenging to estimate due to various overhead costs and loss in production capacities. One can adopt one of the two main approaches to deal with uncertainties. The first method is to model the uncertainties using fuzzy sets theory and the second approach is to use random variables and probability distributions that lead to stochastic programming methods. Having observed patterns of optimal schedules obtained by the exact methods such the one presented in the study, the second area of expansion would be to employ multiobjective meta-heuristics algorithms such NSGAII and NPGA to generate near-optimal solutions for very largescale industrial problems with hundreds of machines and equipment.

\section{REFERENCES}

Aggoune, R., Portmann, M.-C. (2006). Flow shop scheduling problem with limited machine availability: a heuristic approach. International Journal of Production Economics 99 $1-2$, pp. 4-15.

Aghezzaf, E. H., Jamali, M. A., Ait-Kadi, D. (2007). An integrated production and preventive maintenance planning model. European Journal of Operational Research 181 2, pp. 679685.

Aghezzaf, E. H., Khatab, A., LeTam, P. (2016). Optimizing production and imperfect preventive maintenance planning's integration in failure-prone manufacturing systems. Reliability Engineering and System Safety 145, pp. 190-198.

Aghezzaf, E. H., Najid, N. M. (2008). Integrated production planning and preventive maintenance in deteriorating production systems. Information Sciences 178 17, pp. 33823392.

Alaoui-Selsouli, M., Mohafid, A., Naji, N. M. (2012). Lagrangian relaxation based heuristic for an integrated production and maintenance planning problem. International Journal of Production Research 50 13, pp. 3630-3642.

Alimian, M., Saidi-Mehrabad, M., Jabbarzadeh, A. (2019). A robust integrated production and preventive maintenance planning model for multi-state systems with uncertain demand and common cause failures. Journal of Manufacturing Systems 50, pp. 263-277.

Ao, Y., Zhang, H., Wang, C. (2019). Research of an integrated decision model for production scheduling and maintenance planning with economic objective. Computers \& Industrial Engineering 137, pp. Forthcoming.

Assid, M., Gharbi, A., Hajji, A. (2015). Joint production, setup and preventive maintenance policies of unreliable two-product manufacturing systems. International Journal of Production Research 53 15, pp. 4668-4683.

Bahria, N., Chelbi, A., Bouchriha , H., Dridi, I. H. (2019). Integrated production, statistical process control, and maintenance policy for unreliable manufacturing systems. International Journal of Production Research 57 8, pp. 2548-2570.

Bajestani, M. A., Banjevic, D., Beck, J. C. (2014). Integrated maintenance planning and production scheduling with Markovian deteriorating machine conditions. International Journal of Production Research 52 24, pp. 7377-7400.

Boudjelida, A. (2019). On the robustness of joint production and maintenance scheduling in presence of uncertainties. Journal of Intelligent Manufacturing 30, pp. 1515-1530.

Bouslah, B., Gharbi, A., Pellerin, R. (2016a). Integrated production, sampling quality control and maintenance of deteriorating production systems with AOQL constraint. Omega 61, pp. 110-126.
Bouslah, B., Gharbi, A., Pellerin, R. (2016b). Joint economic design of production, continuous sampling inspection and preventive maintenance of a deteriorating production system. International Journal of Production Economics 173, pp. 184198.

Cassady, C. R., Kutanoglu, E. (2003). Minimizing job tardiness using integrated preventive maintenance planning and production scheduling. IIE Transactions 35, pp. 503-513.

Chansombat, S., Pongcharoen, P., Hicks, C. (2018). A mixedinteger linear programming model for integrated production and preventive maintenance scheduling in the capital goods industry. International Journal of Production Research 57 1, pp. 61-82.

Cheng, G. Q., Zhou, B. H., Li, L. (2018). Integrated production, quality control and condition-based maintenance for imperfect production systems. Reliability Engineering \& System Safety 175, pp. 251-264.

Cui, W., Lu, Z., Li, C., Han, X. (2018). A proactive approach to solve integrated production scheduling and maintenance planning problem in flow shops. Computers \& Industrial Engineering 115, pp. 342-353.

Deb, K. (2011), Multi-objective optimisation using evolutionary algorithms: An introduction. In L. Wang, H. C. N. Amos, K. Deb (Eds.), Multi-objective Evolutionary Optimisation for Product Design and Manufacturing (pp. 3-34). London, UK: Springer.

Dhouib, K., Gharbi, A., Ben Aziza, M. N. (2012). Joint optimal production control/preventive maintenance policy for imperfect process manufacturing cell. International Journal of Production Economics 137 1, pp. 126-136.

Duffuaa, S., Kolus, A., Al-Turki, U., El-Khalifa, A. (2020). An integrated model of production scheduling, maintenance and quality for a single machine. Computers \& Industrial Engineering 142, pp. Forthcoming.

Ekin, T. (2018). Integrated maintenance and production planning with endogenous uncertain yield. Reliability Engineering \& System Safety 179, pp. 52-61.

Elsayed, E. A. (2012), Reliability Engineering. Hoboken, New Jersey, USA: John Wiley \& Sons, Inc.

Emami-Mehrgani, B., Neumann, W. P., Nadeau, S., Bazrafshan, M. (2016). Considering human error in optimizing production and corrective and preventive maintenance policies for manufacturing systems. Applied Mathematical Modelling 40 3, pp. 2056-2074.

Ettaye, G., El Barkany, A., Jabri, A., El Khalfi, A. (2018). Optimizing the integrated production and maintenance planning using genetic algorithm. International Journal of Engineering Business Management 10, pp. 1-9.

Fitouhi, M.-C., Nourelfath, M. (2014). Integrating noncyclical preventive maintenance scheduling and production planning fo rmulti-state systems. Reliability Engineering and System Safety 121, pp. 175-186.

Ghaleb, M., Taghipour, S., Sharifi, M., Zolfagharinia, H. (2020) Integrated production and maintenance scheduling for a single degrading machine with deterioration-based failures. Computers \& Industrial Engineering 53, pp. Article 106432.

Gosavi, A. (2015), Simulation-Based Optimization: Parametric Optimization Techniques and Reinforcement Learning. New York, NY, USA: Springer.

Kang, K., Subramaniam, V. (2018). Integrated control policy of production and preventive maintenance for a deteriorating manufacturing system. Computers \& Industrial Engineering 118 , pp. 266-277.

Kolus, A., El-Khalifa, A., Al-Turki, U. M., Duffuaa, S. O. (2020). An integrated mathematical model for production scheduling and preventive maintenance planning. International Journal of Quality \& Reliability Management ahead-of-print aheadof-print, pp. 
Kubiak, W., Blazewicz, J., Formanowicz, P., Breit, J., Schmidt, G. (2002). Two-machine flow shops with limited machine availability. European Journal of Operational Research 136 3 , pp. 528-540.

Kumar, S., Lad, B. K. (2017). Integrated production and maintenance planning for parallel machine system considering cost of rejection. Journal of the Operational Research Society 68, pp. 834-846.

Kuo, Y., Chang, Z.-A. (2007). Integrated production scheduling and preventive maintenance planning for a single machine under a cumulative damage failure process. Naval Research Logistics 54 6, pp. 602-614.

Li, L., Li, M., Liu, Q., Li, S. (2010) Integrated optimization research on preventive maintenance planning and production scheduling. In 2010 International Conference on Management and Service Science. Wuhan, China: IEEE.

Liu, Q., Dong, M., Chen, F. F., Lv, W., Ye, C. (2019). Singlemachine-based joint optimization of predictive maintenance planning and production scheduling. Robotics and ComputerIntegrated Manufacturing 55 B, pp. 173-182.

Lu, Z., Cui, W., Han, X. (2015). Integrated production and preventive maintenance scheduling for a single machine with failure uncertainty. Computers \& Industrial Engineering 80, pp. 236-244.

Machani, M., Nourelfath, M. (2012). A variable neighbourhood search for integrated production and preventive maintenance planning in multi-state systems. International Journal of Production Research 50 13, pp. 3643-3660.

McNeel.com. (2016) A brief explanation of CNC machines and how they work. In.

Moghaddam, K. S., Usher, J. S. (2010). Optimal preventive maintenance and replacement schedules with variable improvement factor. Journal of Quality in Maintenance Engineering 163, pp. 271-287.

Najid, N. M., Alaoui-Selsouli, M., Mohafid, A. (2011). An integrated production and maintenance planning model with time windows and shortage cost. International Journal of Production Research 49 8, pp. 2265-2283.

Nourelfath, M., Chatelet, E. (2012). Integrating production, inventory and maintenance planning for a parallel system with dependent components. Reliability Engineering and System Safety 101, pp. 59-66.

Nourelfath, M., Fitouhi, M.-C., Machani, M. (2010). An integrated model for production and preventive maintenance planning in multi-state systems. IEEE Transactions on Reliability 59 3, pp. $496-506$

Nourelfath, M., Nahas, N., Ben-Daya, M. (2016). Integrated preventive maintenance and production decisions for imperfect processes. Reliability Engineering and System Safety 148 , pp. 21-31.

Pan, E., Liao, W., Xi, L. (2010). Single-machine-based production scheduling model integrated preventive maintenance planning. The International Journal of Advanced Manufacturing Technology 50, pp. 365-375.

Polotski, V., Kenne, J.-P., Gharbi, A. (2019). Joint production and maintenance optimization in flexible hybrid ManufacturingRemanufacturing systems under age-dependent deterioration. International Journal of Production Economics 216, pp. 239 254.
Portioli-Staudacher, A., Tantardini, M. (2012). Integrated maintenance and production planning: a model to include rescheduling costs. Journal of Quality in Maintenance Engineering 18 1, pp. 42-59.

Purohit, B. S., Lad, B. K. (2016). Production and maintenance planning: an integrated approach under uncertainties. The International Journal of Advanced Manufacturing Technology 86, pp. 3179-3191.

Sitompul, C., Aghezzaf, E. H. (2011). An integrated hierarchical production and maintenance planning model. Journal of Quality in Maintenance Engineering 17 3, pp. 299-314.

Sortrakul, N., Cassady, C. R. (2007). Genetic algorithms for total weighted expected tardiness integrated preventive maintenance planning and production scheduling for a single machine. Journal of Quality in Maintenance Engineering 13 1, pp. 49-61.

Sortrakul, N., Nachtmann, H. L., Cassady, C. R. (2005). Genetic algorithms for integrated preventive maintenance planning and production scheduling for a single machine. Computers in Industry 56, pp. 161-168.

Suliman, S. M. A., Jawad, S. H. (2012). Optimization of preventive maintenance schedule and production lot size. International Journal of Production Economics 137 1, pp. 19-28.

Tekin, E., Sabuncuoglu, I. (2004). Simulation optimization: A comprehensive review on theory and applications. IIETransactions 36 11, pp. 1067-1081.

Uzun, A., Ozdogan, A. (2012). Maintenance parameters based production policies optimization. Journal of Quality in Maintenance Engineering 18 3, pp. 295-310.

Wang, S. (2013). Bi-objective optimisation for integrated scheduling of single machine with setup times and preventive maintenance planning. International Journal of Production Research 51 12, pp. 3719-3733.

Wang, S., Liu, M. (2013). A branch and bound algorithm for singlemachine production scheduling integrated with preventive maintenance planning. International Journal of Production Research 51 3, pp. 847-868.

Wang, S., Liu, M. (2015). Multi-objective optimization of parallel machine scheduling integrated with multi-resources preventive maintenance planning. Journal of Manufacturing Systems 37 1, pp. 182-192.

Xiao, L., Song, S., Chen, X., Coit, D. W. (2016). Joint optimization o fproduction scheduling and machine group preventive maintenance. Reliability Engineering \& System Safety 146, pp. $68-78$

Yalaoui, A., Chaabi, K., Yalaoui, F. (2014). Integrated production planning and preventive maintenance in deteriorating production systems. Information Sciences 278, pp. 841-861.

Yildirim, M. B., Nezami, F. G. (2014). Integrated maintenance and production planning with energy consumption and minimal repair. The International Journal of Advanced Manufacturing Technology 74, pp. 1419-1430.

Yulan, J., Zuhua, J., Wenrui, H. (2008). Multi-objective integrated optimization research on preventive maintenance planning and production scheduling for a single machine. The International Journal of Advanced Manufacturing Technology 39, pp. 954-964.

Zhao, S., Wang, L., Zheng, Y. (2014). Integrating production planning and maintenance: an iterative method. Industrial Management \& Data Systems 114 2, pp. 162-182.

Dr. Kamran Moghaddam is an Associate Professor of Supply Chain Management in the College of Business at Clayton State University. He received his BS in Applied Mathematics from the University of Tehran, MS in Industrial Engineering from Amirkabir University of Technology and his $\mathrm{PhD}$ in Industrial Engineering from the University of Louisville. Over the past 19 years, Dr. Moghaddam has been active in the field of industrial engineering and operations management in academic and industry environments. He has conducted or been involved in variety of projects such as multi-reservoir systems operations management, transportation and logistics systems design and improvement, optimal maintenance scheduling in manufacturing systems, development of a decision support system for healthcare and public health protection, and reverse 
Moghaddam: A Multi Objective Modeling Approach for Integrated Manufacturing and Preventive Maintenance Planning Operations and Supply Chain Management 14(1) pp. 83 - 99 @ 2021

logistics systems design and evaluation. Dr. Moghaddam is a licensed Professional Engineer (PE) and a Certified Quality Engineer (CQE) by American Society for Quality. 